\title{
A imagem do Rio de Janeiro através dos cartões-postais
}

\author{
The image of Rio de Janeiro through postcards
}

\author{
1 Suelen Cristina Almeida de Souza \\ ${ }^{2}$ Marcio dos Santos Borges
}

1 Universidade Estácio de Sá
2 Universidade Estácio de Sá

\section{RESUMO}

Este artigo tem por finalidade apresentar algumas considerações quanto aos investimentos da imagem da cidade do Rio de Janeiro por meio de cartões-postais. A proposta, que se fundamenta nos pressupostos teóricos de Mário Carlos Beni e John Urry, busca problematizar os locais da cidade que são destaques nos cartões-postais, a partir de pesquisa realizada em bancas de jornal da Zona Sul do Rio de Janeiro. Tal pesquisa aponta o uso do "lugar comum" na divulgação da cidade do Rio de Janeiro, considerando a inexistência de cartõespostais que contemplem outras áreas de potencial turístico, tais como: Quinta da Boa Vista, Feira de São Cristóvão e Mercadão de Madureira - para citarmos alguns. Por outro lado, os cartões-postais se concentram no imaginário midiático do Rio de Janeiro: Cristo Redentor, Pão de Açúcar, Futebol e a praia de Copacabana, além da oferta de imagens de muitas favelas cariocas e mulheres seminuas. Por tal perspectiva, o artigo aponta para a necessidade de otimização do potencial turístico do Rio de Janeiro, cuja falta de investimento turístico na "geografia da cidade" leva à ausência de outros atrativos, o que, consequentemente, contribui para a falta de demanda turística nas regiões para além da Zona Sul carioca.

\section{Palavras-chave}

Turista; cartão-postal; imagem; Rio de Janeiro.

\begin{abstract}
This article aims to present some considerations regarding the investment image of the city of Rio de Janeiro through postcards. The proposal, which is based on theoretical assumptions of Carlos Mario Beni and John Urry, seeks to question the city's sites are featured on postcards from research conducted at newsstands in the South Zone of Rio de Janeiro. Such research shows the use of "commonplace" in the disclosure of the city of Rio de Janeiro considering the lack of postcards addressing other tourist potential of areas such as: Quinta da Boa Vista, Fair Saint Kitts and Mercadão Madureira - to We cite a few. On the other hand, the postcards are concentrated in the media imagery of Rio de Janeiro: Christ Redeemer, Sugar Loaf, Football and the Copacabana beach, in addition to offering images of many slums and scantily clad women. For this perspective, the article points to the need to optimize the tourist potential of Rio de Janeiro whose lack of tourism investment in the "geography of the city" leads to the absence of other attractive, which in turn contributes to the lack of tourist demand in the regions to beyond the South Zone of Rio.
\end{abstract}

\section{Keywords}

Tourist; postcards; images; Rio de Janeiro.

\section{Como você deve citar?}

SOUZA, Suelen Cristina Almeida de; BORGES, Marcio dos Santo. A imagem do Rio de Janeiro através dos cartões-postais. Cadernos UniFOA, Volta Redonda, n. 28, p. 41-49, ago. 2015. 


\section{INTRODUÇÃO}

A imagem que o setor do Turismo cria de uma localidade é importante de várias maneiras, não só para o marketing e os serviços, mas também para a população local já que se trata da imagem da sua suposta identidade. Contudo, o Turismo ainda precisa ser compreendido não só como um setor voltado para o lucro e a geração de empregos, mas como imprescindível ao favorecimento do desenvolvimento regional, da preservação do meio ambiente e da cultura, da satisfação e das necessidades dos indivíduos.

O marketing de destinos é, às vezes, confundido com o rótulo alternativo de imagem do destino, porém aquele é mais amplo e proporciona uma estrutura ou um referencial mais preciso para administrar a reputação total ou a identidade da destinação, e a maneira com que essa reputação influencia a capacidade de um destino de atrair visitantes (BENI, 2007).

Nesse sentido, pensar o setor turístico é compreender a complexidade que a atividade suscita, envolvendo inúmeros setores de serviços e trabalhando em parceria, tais como: operadoras, companhias aéreas e hotéis, que, por sua vez, necessitam de um emaranhado de atividades conexas para que o produto final consiga atingir o esperado.

Os produtos turísticos são todos intangíveis e, portanto, é no trabalho incessante de divulgação de imagem positiva que o "consumidor turista" se interessa por um destino específico e os serviços ali oferecidos. O Rio de Janeiro retratado nos cartões-postais é, por exemplo, um dos veículos essenciais de investimento do setor turístico na divulgação da cidade.

Este trabalho teve como objetivo abordar, através de uma análise dos cartões-postais, a questão da imagem do Rio de Janeiro, a qual tem sempre como as primeiras imagens a serem exibidas e vendidas, o Cristo Redentor, o Pão de Açúcar, Copacabana, as praias, o Maracanã e o futebol, o samba e o carnaval, tornando o postal uma mídia influenciadora na decisão de compra do consumidor.

O direcionamento do olhar do turista implica, frequentemente, em diferentes formas de padrões sociais, com uma sensibilidade voltada para os elementos visuais da paisagem do campo e da cidade, muito maior do que aquela que é encontrada normalmente na vida cotidiana. As pessoas se deixam ficar presas por esse olhar, que é visualmente objetificado ou capturado através de fotos, cartões-postais, filmes, modelos, etc. Eles possibilitam ao olhar ser reproduzido e recapturado incessantemente (URRY, 2001).

Trata-se de uma dependência produtiva. 0 consumidor de serviços tem como característica essencial comprar o "produto viagem" sem ter a plena certeza da satisfação. Uma boa escolha no momento da compra depende, entre outros fatores, da imagem que tenha do destino.

\subsection{Turismo e imagem}

A Organização Mundial do Turismo (OMT) define Turismo como: "a soma de relações e de serviços resultantes de um câmbio de residência temporário e voluntário motivado por razões alheias a negócios ou profissional". De acordo com a OMT, o turista é a pessoa que desloca para fora do seu local de residência permanente por mais de 24 horas, pernoita, por motivo outro que o de não fixar residência ou exercer atividade remunerada, realizando gastos de qualquer espécie com renda recebida fora da região visitada. 
Os elementos mais importantes são o tempo de permanência, o caráter não lucrativo da visita e, uma coisa que é pouco explorada pelos autores analisados, a procura por prazer por parte dos turistas. 0 Turismo é uma atividade em que a pessoa procura prazer por livre e espontânea vontade. Portanto a categoria de livre escolha deve ser incluída como fundamental no estudo do Turismo (BARRETO, 2003).

Sendo assim, entende-se que praticar Turismo é viajar por lazer para algum lugar diferente do local que reside, buscando satisfazer suas necessidades, na maioria das vezes, buscando uma "fuga" do cotidiano fortemente influenciado pela imagem, que é divulgada nos pacotes turísticos, pois consumir o belo se torna mais prazeroso, ou seja, embora um destino turístico ofereça inúmeros atrativos com potencial para uma grande demanda, deve-se levar em consideração toda a infraestrutura que torne 0 núcleo receptor atraente, aumentando, dessa forma o desenvolvimento do Turismo local.

De acordo com Kotler, Haider e Rein et alli (1995), as imagens são um conjunto de ideias formadas sobre um local, apresentam-se como uma simplificação de várias associações e informações ligadas ao mesmo tempo e são produtos de essência que se tira através de dados, impressões, crenças e ideias que as pessoas têm sobre ele.

Ambos revelam que imagem é tudo aquilo que somos capazes de ver e julgar ser feio ou belo.

De acordo com Lynch, as pessoas utilizam os caminhos, limites, bairros, pontos nodais e marcos, para projetar sua imagem da cidade. 0 autor conclui também que não há como conhecer toda a cidade de uma só vez, pois é necessário tempo, e que nada é experimentado individualmente, e sim em relação a seu entorno. Elementos semelhantes, porém localizados em contextos diferentes, adquirem significados também diferentes.

\subsection{O Rio de Janeiro e sua imagem}

A cidade do Rio de Janeiro foi "descoberta" no dia $1^{\circ}$ de janeiro de 1502, passando pela sua fundação no ano de 1555, até chegar ao ano de 1753 , quando a cidade vira capital, não sendo preciso fazer muito para adquirir a imagem de "paraíso urbano - tropical".

A cidade tendo sido, por dois séculos, o principal centro político e cultural do país, fornece uma ampla variedade de lugares históricos e culturais. O Rio de Janeiro possui um papel de protagonista na história da vida política e cultural brasileira, e essa posição de destaque interfere na identidade carioca sobre o imaginário nacional, principalmente pelas telenovelas, o que amplia ainda mais o campo de influências da cidade do Rio. Assim, turistas de todos os continentes se deslocam para o Rio no intuito de conhecer esse local possuidor de uma beleza natural. Para o estrangeiro, a cidade do Rio de Janeiro continua sendo vista como espelho do Brasil, e, de longe, a principal atração turística brasileira (CASTRO, 2001).

Dentro de um imaginário já sedimentado da compreensão do Brasil, a cidade do Rio de Janeiro ocupa um lugar de destaque, considerada uma das capitais brasileiras mais atraentes e, embora a violência urbana da cidade seja exposta pelos meios de comunicação, consegue mesmo assim atrair um grande número de turistas todos os anos. Os cartões-postais não têm o mesmo peso de divulgação de alguns anos, mas mesmo com a internet e outros meios digitais, continuam tendo importância na divulgação dos destinos turísticos, inclusive pelos cartões digitais.

Conhecida como "cidade maravilhosa" desde a primeira metade do século XX, o Rio de Janeiro possui atrativos naturais que lhe conferem notoriedade internacional - e tal característica é associada, principalmente, pelo referencial da beleza natural. 
A história do turismo no Rio de Janeiro tem como marco a utilização de elementos da cultura local como atrativo turístico, o qual é pensado para reforçar tanto a identidade cultural quanto a memória da cidade. Castro (2001) destaca o período em que o Rio de Janeiro foi inserido no cenário turístico internacional. A cidade é rica em aspectos culturais, pois possui diversos museus, igrejas com arquitetura marcante de épocas importantes na história da cidade, além de ainda ostentar, de forma bem conservada, locais que serviam para encontros da alta sociedade carioca dos séculos passados, como a Confeitaria Colombo.

Na década de 1920, acontece a "construção" de "um jeito carioca de ser": malandro, preguiçoso, amante da praia e do futebol. O personagem Zé Carioca, de Walt Disney, é um dos exemplos da maneira como esse imaginário é difundido. Cabe aqui ressaltar que o personagem desponta no cenário das histórias em quadrinhos de Walt Disney em um fato crucial da história da humanidade, a Segunda Guerra Mundial. É interessante notar que de todos os personagens em quadrinhos de Walt Disney, somente o Zé Carioca é quem vai ter definida abertamente a sua nacionalidade - um papagaio brasileiro (MENDES, 2003).

O papagaio, ave tropical verde-amarela que faz ver, de imediato, a sua ligação com o pendão nacional é a parte afetiva de nosso anedotário popular, indicando a irreverência e a hilaridade picante de nossa alma humorística tupiniquim. (...) E o malandro, personagem célebre da vida nacional, e, mais especificamente da vida carioca, exatamente porque caiu no domínio popular como a representação mais que perfeita desse ator social. Essa conjunção de fatores formais e culturais produziu um dos personagens mais conhecidos e apreciados das histórias em quadrinhos no Brasil (MENDES, 2003).

É importante ressaltar que a visão do turista é diferente da que a maior parte da população possui, pois para esta, os atrativos são apenas aqueles caracterizados e divulgados pela mídia como pontos turísticos, por exemplo, o Cristo Redentor, Pão de Açúcar, entre outros, porém o turista deseja também conhecer o cotidiano das cidades. Os cartões-postais têm o potencial de mostrar realmente que o Rio de Janeiro é muito mais que futebol, praia e carnaval.

O papel da mídia é estabelecer uma mediação entre a fonte de uma informação e os espectadores/ouvintes/leitores/telespectadores. Tal proposta de mediação, no entanto, não exclui que cada um dos indivíduos que recebam informações exerça uma atitude crítica e filtre as informações recebidas, criando uma opinião própria, particular - que muitas vezes pode estar "em acordo" com a opinião pública ou não.

Embora a cidade do Rio de Janeiro não seja divulgada da melhor maneira no exterior e até mesmo no Brasil, ela conquista um grande fluxo de turistas todos os anos. De acordo com a Infraero (Empresa Brasileira de Infraestrutura Portuária), o fluxo de turistas no Rio de Janeiro, em 2011, foi de 1.044 .931 e, em 2012, de 1.164.187.

O Rio de Janeiro é uma cidade litorânea e isso faz com que as praias sejam o principal destino a ser visitado tanto pelos turistas como para os moradores, sendo fácil observar mulheres de biquínis, principalmente, no verão, quando o atrativo é mais procurado. Nessa imagem das mulheres na praia, quando associada ao cartão-postal, podemos perceber uma nova conotação ao uso de uma vestimenta comum no verão brasileiro - a sexualidade das mulheres é destacada e o biquíni ganha um apelo sexual, deslocando o destino turístico da beleza natural da praia para o apelo sexual, o que confirmamos nesta pesquisa em alguns cartões-postais analisados. Devemos levar em consideração que tal imagem possa contribuir com o "turismo sexual", fazendo com que a primeira imagem do turista sobre a cidade seja: a cidade sem regras, liberta de ética. De acordo com esse ponto de vista, seria no trópico, lugar 
exótico, que o turista estrangeiro encontraria a mulher em seu estado quase natural. A proximidade com a praia, com a paisagem natural reforça essa imagem.

A imagem da mulher seminua começou a ser veiculada após o conceito dado ao Rio de Janeiro: "A cidade Maravilhosa", quando foi divulgada a principal festa popular do país: o carnaval, em que muitas mulheres permanecem "nuas" com o intuito de fazer a propaganda da cidade, ainda hoje, tal imagem da mulher sendo também divulgada em revistas, principalmente quando está chegando o verão. As imagens de mulheres nas praias têm mais repercussão nas praias que possuem mais apelo turístico, como Copacabana e Ipanema.

Em 2005, a Assembleia Legislativa do Estado do Rio de Janeiro aprovou por unanimidade o projeto de lei $2813 / 2005$, que "proíbe a veiculação, exposição e venda de postais turísticos que usem fotos de mulheres, em trajes sumários, que não mantenham relação ou não estejam inseridas na imagem original dos cartões-postais". O projeto da Deputada Estadual Alice Tamborindeguy, hoje do PP (Partido Progressista), abre espaço para uma reflexão sobre as relações entre corpo, estado, turismo e mídia (SIQUEIRA; SIQUEIRA, 2007).

Ao mesmo tempo em que a imagem da mulher seminua nos cartões-postais foi proibida, a imagem da mulher seminua divulgada no carnaval pode ser vendida por fazer parte da cultura local, basta o estado saber diferenciar os sentidos e significados das imagens, uma tarefa difícil tanto para quem produz a imagem quanto para quem vê.

Para trabalhar a imagem brasileira de uma forma geral, em especial a do Rio de Janeiro, em 18 de novembro de 1966, foi criada a EMBRATUR, uma empresa brasileira que tem como objetivo desenvolver a atividade do Turismo no Brasil, gerando emprego em todo setor turístico. Hoje, concentra-se na promoção, no marketing e apoio à comercialização dos produtos, serviços e destinos turísticos, além de ter a responsabilidade de levar a marca e as imagens do Brasil para o exterior.

De acordo com o Ministério do Turismo, para a divulgação do Brasil no exterior, foi elaborada, em 2005, uma marca - Marca Brasil, sendo o símbolo que passou a representar a imagem do país inteiro. Desenvolvida durante um ano pelo Instituto Brasileiro de Turismo (EMBRATUR) dentro do Projeto Aquarela, que estabelece ações do marketing de Turismo para os próximos anos.

A marca foi desenvolvida a partir de pesquisas de percepção da imagem do Brasil em 19 mercados alvo com mais de seis mil pessoas, entre turistas estrangeiros em visita ao país, operadores internacionais de Turismo e potenciais turistas. As pesquisas definiram as diretrizes para a criação do logotipo - multicolorido, inspirado em uma aquarela do paisagista Roberto Burle Marx, que insinua a diversidade cultural e natural do país. 0 verde representa as florestas; o amarelo, clima, calor e luz; o azul, as águas e o céu; o branco, o sincretismo religioso e o vermelho e laranja, as festas populares.

\subsection{Cartão-postal como meio de divulgação}

Uma das melhores formas de divulgar a imagem de uma cidade é através dos cartões-postais, pois as pessoas se sentem atraídas pelas imagens dos atrativos postados, querendo assim conhecer pessoalmente tamanha beleza.

Além de servir como divulgação, é uma forma atrativa de compartilhar a sensação de estar visitando tal destino, pois nele a pessoa pode escrever uma mensagem para quem deseja enviar, podendo, dessa maneira, dizer o quanto gostou de visitar a cidade. Esse ato contribui muito na decisão de compra de um turista, pois quando uma pessoa diz que gostou de visitar um destino, começa a surgir interesse 
em outras pessoas, pois o produto turístico é um produto intangível, a pessoa só tem certeza de que fez uma boa compra no momento que chega ao destino e usufrui o que comprou.

Muitas pessoas em todo o mundo colecionam cartões-postais, pois é uma das melhores maneiras de comparar como era uma cidade antigamente e atualmente. Além disso, numa coleção de cartões-postais as pessoas podem estudar e pesquisar a história, geografia, modo de vida, usos e costumes de povos e países, sociologia, urbanismo, meios de transporte e ainda a própria evolução da fotografia e da indústria gráfica.

De acordo com a Associação de Cartofilia do Rio de Janeiro (ACARJ), colecionar cartões-postais é um hábito antigo no mundo, existindo associações que administram a coleção. A ACARJ é uma sociedade civil, sem fins lucrativos, fundada em 19 de dezembro de 1985, em reunião de cartofilistas, na residência do Dr. Carlos Wehrs, na Rua Senador Vergueiro, 154, apto. 1203, no Rio de Janeiro (RJ). A mesma permaneceu aberta durante 30 dias para assinatura de todos os que quisessem participar da iniciativa, como sócios fundadores. 0 cartão-postal, como vetor de imagens, supria, através do mundo, a falta desses meios de divulgação.

O postal é considerado o principal meio de veiculação da imagem fotográfica na virada do século XIX e nas primeiras décadas do século XX. Pode ser entendido como o início do processo de globalização por meio da imagem de um mundo que se internacionalizava pelo comércio e pelo fluxo migratório sem precedentes até então.

Os cartões-postais podem ser encontrados na internet, em revistas e etc., mas o perfil do cartão-postal é uma cartolina em forma de quadrado vendida principalmente em bancas de jornal, sendo assim mais divertido de presentear alguém com a imagem do destino visitado.

A partir da análise da venda do postal, realizada no total de dez bancas de jornal na Zona Sul carioca, constatou-se que, apesar da diversidade de atrativos que a cidade dispõe, muitos ainda não estão incluídos nos roteiros turísticos do Rio de Janeiro e, portanto, não são vendidos. Percebe-se que apenas são vendidas as imagens incluídas nos roteiros tradicionais. Pode-se perceber também que os postais são sempre expostos na entrada das bancas, podendo considerar que servem para a decoração e um alvo para atrair turistas.

As bancas costumam vender os postais por mais ou menos $R \$ 2,00$ independente da imagem vendida. Ainda são poucas as imagens vendidas nas bancas, sendo as mais encontradas: o Pão de Açúcar, o Cristo Redentor, o Maracanã e a praia de Copacabana, muitas vezes todos em um só postal em forma de montagem e, às vezes, também julgados como maravilhas da cidade.

As imagens mais vendidas da cidade do Rio de Janeiro ainda são as imagens dos atrativos naturais, que são as mais procuradas justamente pela cidade ter a fama de conter as mais belas paisagens naturais do mundo.

Há uma diversidade entre a região onde bancas se localizam e as imagens dos postais, isto é, pode-se perceber que as imagens de mulheres seminuas nas praias são encontradas em diversas bancas, mas é encontrada com mais facilidade nas bancas localizadas próximas às praias, por estarem mais próxima à realidade da imagem e pelo fato de as praias serem um dos entretenimentos que os turistas mais frequentam.

De acordo com Siqueira e Siqueira (2007), destinos turísticos como a cidade do Rio de Janeiro, isto é, complexos, contraditórios e exóticos, vendem suas imagens em revistas, diversos meios de 
comunicação para conseguir atrair os olhos dos turistas. Tais imagens vendidas não estão somente no "olhar" dos visitantes, como também dos próprios moradores locais, no qual tais imagens vendidas fazem parte do seu cotidiano.

Contrariando a ideia de que os cartões-postais divulgam apenas o que há de bom em uma cidade, foi encontrada a venda, nas bancas, postais com imagens de favelas / morros, tais como o morro Dona Marta e da Providência. Podemos concluir que, atualmente, a cidade do Rio de Janeiro está expondo, através da mídia, um fato vivenciado em muitas cidades - a desigualdade social. Percebe-se que até mesmo problemas sociais conseguem atrair turistas, pois, muitas vezes, os turistas têm interesse em conhecer favelas - Favela Tours, por querer vivenciar o cotidiano de todas as classes cariocas.

Ainda há muito para ser divulgado sobre a cidade maravilhosa, como por exemplo, atrativos em potencial da zona norte carioca, como a Quinta da Boa Vista, diversas trilhas, o Mercadão de Madureira, a Igreja Nossa Senhora da Penha, a Feira de São Cristóvão, entre outros. Portanto a prefeitura, juntamente com o governo, deve investir mais nos atrativos e no trabalho de divulgação e, consequentemente, na reputação da cidade, para que, dessa forma, o Rio de Janeiro consiga não só atrair mais visitantes, como também atingir uma ótima imagem na concepção de todos, desenvolvendo a cidade e obtendo um maior fluxo de turistas na região.

O cartão-postal é um meio que tem por objetivo fazer com que o turista se sinta atraído pelo local de destino exposto na imagem, porém devemos levar em consideração que não basta apenas expor a imagem e sim criar meios que façam com que o entorno do atrativo esteja em condições para atender o turista. Dessa maneira, é necessário o Rio de Janeiro administrar a infraestrutura turística da cidade para conseguir atingir uma demanda em potencial.

O Turismo receptivo é fundamental para se organizar a imagem de um destino e, para isso, precisa ser bem estruturado e necessita do apoio de três elementos essenciais para que esse planejamento seja executado com sucesso. De acordo com o Ministério do Turismo, são eles:

- Relação Turismo x Governo em harmonia;

- Apoio e investimentos dos empresários;

- Envolvimento.

Levando em consideração o desenvolvimento de outras cidades no exterior como Nova lorque e Paris, pode-se analisar a ideia de revitalizar todos atrativos ainda não conhecidos e frequentados na cidade do Rio de Janeiro, afastando até mesmo o próprio carioca, por não terem um projeto de infraestrutura similar ou que consiga "atrair os olhos dos turistas".

Podemos também lembrar que muitos atrativos continuam sendo os mais procurados para visita. Um dos exemplos é a Lapa que, mesmo conseguindo atrair milhões de turistas e sendo frequentada, principalmente por ser um atrativo que atende a todas as classes, consegue fazer com que o turista leve uma imagem, muita vezes, ruim da cidade, já que no entorno é possível se deparar com problemas sociais evidentes, tais como a prostituição e a violência. Tais aspectos fazem com que os estrangeiros e até mesmo brasileiros tenham essa imagem negativa do Rio de Janeiro, o que impede que a cidade seja conhecida e compreendida de fato como cidade maravilhosa. 


\section{CONSIDERAÇÕES FINAIS}

O Rio de Janeiro é uma cidade que, embora receba todo ano um grande número de turistas, ainda é carente de investimento de marketing turístico, ou seja, é necessário divulgar toda a oferta de atrativos, além de trabalhar a reputação do destino que ainda tem o conceito de uma cidade sem regras e sem limites.

O postal é um meio de comunicação que tem como objetivo divulgar o que há de bom em uma cidade, diferente dos demais, tais como, jornal, televisão etc. Embora também já tenha causado um pouco de polêmica, a partir da divulgação da mulher de biquíni nas praias, essa realidade de entretenimento no cotidiano dos cariocas se transformou em um alvo para atrair turistas, fato não explícito, quando iniciou a venda dos postais e quando esse tipo de mídia ainda divulgava imagens em preto e branco, tendo como principal intenção utilizar esse meio como lembrança a quem não teve o prazer de deslumbrar o belo de perto, facilitando a comunicação. Porém ao fazer a análise para este artigo, foi percebida a venda de cartões-postais com imagem de algumas favelas existentes na cidade do Rio de Janeiro, tais como: Comunidade Dona Marta e Morro da Providência.

Na década de 90, a favela não era cartão-postal (inclusive sentido pelos moradores, como se vê no funk da comunidade). Agora é possível perceber que esse espaço agrega novos valores à cidade do Rio de Janeiro, como sentimento de pertencimento, alegria, sobrevivência, o que pode ser percebido no trecho da música que diz: "Nunca vi cartão-postal que se destaque uma favela. Só vejo paisagem muito linda e muito bela. Quem vai pro exterior da favela sente saudade. 0 gringo vem aqui e não conhece a realidade" (VAGALUME, Rap da Felicidade, 1995).

A partir dessa percepção, conclui-se que o cartão-postal não tem divulgado atualmente apenas o que antes era tradicionalmente turístico (praias, carnaval e samba), mas também um espaço sem atrativos econômicos na cidade, como se presumia anteriormente. Com isso, o que se percebe nos cartões-postais comercializados é que há a presença da favela como espaço da cidade, mas não como um espaço turístico, já que as imagens não mostram a favela como espaço de entretenimento turístico e de interesse ao "olhar do turista" (URRY, 2001).

Tal prática, na verdade, corrobora sutilmente com essa "presença/ausência", onde a favela continua ligada a uma imagem negativa - apenas como uma paisagem próxima a belas praias e não como aquele local em que atividades podem ser desenvolvidas.

Embora a cidade possua problemas sociais, como segurança, ainda consegue atender as necessidades dos moradores locais e as dos turistas. A cidade do Rio de Janeiro dispõe de inúmeros entretenimentos e de fácil acesso aos atrativos que, comparada a outras cidades, ainda estão em processo de desenvolvimento.

Podemos concluir que é necessária a importância da preparação do turismo e de uma profissionalização, ou seja, entender o que é o turismo, e entender que a cidade precisa ter uma estrutura, além da paisagem turística, pois assim se ganha mais investimento quando o turista tem interesse em visitar o local e permanecer neste por um período maior, consequentemente, estimulando o carioca a crer que a região tem inúmeros atrativos a oferecer, embora tenha muitos problemas sociais. Portanto, a prefeitura deve enxergar o postal como uma grande potencialização no Rio de Janeiro e, a partir disso, ofertar as imagens turísticas em potencial para todos, isto é, para turistas do mundo todo, para que estes escolham conhecer a cidade que, de fato, é uma cidade maravilhosa e que merece ser visitada. 


\section{REFERÊNCIAS}

ACARJ. Associação de Cartofilia do Rio de Janeiro: A serviço da memória nacional. Rio de Janeiro, 1993. Disponível em: <http://www.brasilcult.pro.br/cartofilia/cartofilia.htm>. Acesso em 06 jun. 2010.

ALERJ. Assembléia Legislativa do Rio de Janeiro. Ementa do projeto de lei 2813/2005. Disponível em: <http://alerjln1.alerj.re.gov.br>. Acesso em 10 mai. 2010.

BARRETO, M. Manual de Iniciação ao Estudo do Turismo. 17. ed. Campinas, SP. Papirus, 2003.

BENI, M. Análise Estrutural do Turismo. 12. ed. São Paulo: Saraiva, 2007.

CASTRO, C. "A Natureza Turística do Rio de Janeiro". In: BANDUCCI, 2001.

CIDINHO; DOCA. Rap da Felicidade. Letra e Vídeo. Disponível em: <http://www.vagalume.com.br/mcscidinho-e-doca/rap-da-felicidade.html>. Acesso em 25 Jun. 2010.

EMBRATUR. Ministério do Turismo. Brasília, nov, 2006.

IBGE. Economia do Turismo - uma perspectiva macroeconômica 2000-2005. Disponível em: <http:// www.ibge.gov.br/home/estatistica/economia/industria/economia_turismo/2000_2005/default.shtm>. Acesso em 01 Jan. 2014.

KOTLER,Philip; HAIDER,Donald H.; REIN,Irving. Marketing Público: como atrair investimentos, empresas, e turismo para cidades, regiões, estados e países. Trad. Eliane Kanner. São Paulo: Makron Books do Brasil, 1995.

LYNCH, Kevin. The image of the city. Cambridge: The M.I.T. Press, 1960.

MENDES, M. A. Malandragem no Imaginário Nacional. Um estudo sobre a construção do personagem Zé Carioca e suas relações com a cultura brasileira. BH, Minas Gerais, 2003.

Secretaria Nacional de Políticas de Turismo. Ministério do Turismo. Anuário Estatístico de Turismo - 2013. Disponível em: <http://www.dadosefatos.turismo.gov.br/export/sites/default/dadosefatos/ anuario/downloads_anuario/Anuxrio_Estatistico_de_Turismo_-_2013_-_Ano_base_2012_Versxo_Set2013. pdf>. Acesso em 15 jul. 2014.

SIQUEIRA, Euler David de, SIQUEIRA, Denise da Costa Oliveira. Corpo, mito e imaginário nos postais das praias cariocas. In: XXVIII Congresso Brasileiro de Ciências da Comunicação. Anais. Rio de Janeiro: UERJ, set./ 2005. Ementa do projeto de lei 2813/2005. Disponível em: < http://alerjln1.alerj.re.gov.br>. Acesso em 09 mai. 2006.

URRY, J. O olhar do Turista, lazer e viagens nas sociedades contemporâneas. São Paulo: Senac. Studio Nobel: SESC, 2001. 